Article

\title{
Residents' Attitude toward Aboriginal Cultural Tourism Development: An Integration of Two Theories
}

\author{
Chi-Ming Hsieh ${ }^{1}$, Bi-Kun Tsai ${ }^{2}$ and Han-Shen Chen ${ }^{3,4, *}$ \\ 1 International Bachelor Program of Agribusiness, National Chung Hsing University, \\ Taichung City 40227, Taiwan; hsiehch9@nchu.edu.tw \\ 2 Graduate Institute of Bio-Industry Management, National Chung Hsing University, \\ Taichung City 40227, Taiwan; pktsai@dragon.nchu.edu.tw \\ 3 Department of Health Diet and Industry Management, Chung Shan Medical University, \\ Taichung City 40201, Taiwan \\ 4 Department of Medical Management, Chung Shan Medical University, Taichung City 40201, Taiwan \\ * Correspondence: allen975@csmu.edu.tw
}

Academic Editor: Vinod Sasidharan

Received: 5 May 2017; Accepted: 23 May 2017; Published: 27 May 2017

\begin{abstract}
Understanding residents' attitudes is critical for successfully developing cultural tourism in aboriginal protected areas. This study developed an integration model combining two theories to identify the key determinants of indigenous residents' attitudes toward cultural tourism development. Social exchange theory stresses the impact of the benefits derived from tourism on indigenous residents' attitudes toward tourism development. Social capital theory embeds clear rationales for strengthening the internalization process of the formation of residents' shared values and understanding, enabling them to trust each other and thus support tourism development. The present study was conducted within two indigenous communities in Eastern Taiwan. The results revealed that cultural tourism benefits and structural and relational capital effectively predict indigenous residents' attitudes toward tourism development; structural capital plays a critical mediating role in the relationship between tourism benefits and residents' attitudes. The managerial implications provide recommendations for aboriginal community developers or practical sectors to avoid problems or costs caused by tourism development when promoting cultural tourism activities within indigenous communities.
\end{abstract}

Keywords: social exchange theory; social capital theory; aboriginal cultural tourism development

\section{Introduction}

Cultural tourism now accounts for nearly $40 \%$ of global outbound travel and market share [1]. Aboriginal cultural tourism is a type of tourism and travel that is motivated or enriched by experiencing aboriginal culture, history, and native people's lifestyles [2] or regional tourism based on local cultural values [3]. From an industrial perspective, aboriginal tourism refers to the facet of tourism activities or industry involving indigenous people [4]; tourism should support indigenous cultures by respecting indigenous knowledge and encouraging residents to value their own traditions and cultural heritage [5]. Although aboriginal cultural tourism has received much attention because of its unique cultural heritage and living traditions that have attracted tourists in recent years, increasing concern has been expressed about tourism's negative impacts on the fragile environment and its indigenous population [6].

Residents' attitudes are key in the process of developing sustainable tourism in aboriginal villages [7]. A community is comprised of different residents and individuals who not only live in 
close geographical proximity but who also have common goals and interests [8]. A community should prioritize the overall interests of local residents and consider both individual consciousness, collective participation, and cohesion establishment [9,10] to achieve community sustainability [11]. Indigenous people develop patterns of natural resource use and practices of human resource management that reflect their detailed knowledge of local geography and their ecosystem to preserve their environment and culture through their living practices [12]. By participating in tourism activities with dignity and self-respect [5], indigenous residents can involve themselves in and control the industry's operation by having their culture serve as the essence that attracts tourists $[13,14]$. Moreover, residents may exhibit the uniqueness of their indigenous cultural identity to an international audience and profit from the internationalization and locally controlled commercialization of local cultural values. Additionally, by commercializing cultural values, local communities can ensure proper funding for cultural projects and preservation [3]. The role of social capital in determining residents' attitudes and behaviors for supporting cultural tourism development has become increasingly vital $[15,16]$, particularly in indigenous communities. Providing a thorough understanding of this critical topic is necessary to improve the sustainability of aboriginal cultural tourism by researchers, practitioners, and marketers. Thus, this study developed and tested integrated models based on both social exchange theory (SET) and social capital theory (SCT) to investigate the determinants of residents' attitudes toward aboriginal cultural tourism development.

The remainder of this paper proceeds as follows. In Section 2, we review the literature on SET and SCT and develop hypotheses for the relationships between them. Section 3 describes our research methodology, including data collection, construction, and measurement. Our data analysis procedures, using structural equation modeling, are provided in Section 4. Section 5 presents discussions and the managerial implications of the findings, and we conclude with limitations and suggestions for future research.

\section{Literature Review}

\subsection{Social Exchange Theory}

SET is a general sociological theory focusing on understanding the exchange of resources and patterns of interaction between individuals and groups $[17,18]$. SET claims that people evaluate or exchange on the basis of the costs and benefits incurred as a result of the exchange [19-21]. From the standpoint of tourism development, stakeholders' attitudes toward and support for tourism development in their community is influenced by their evaluations of the actual and perceived outcomes tourism provides in their community $[19,20]$. For instance, the sociocultural influence of aboriginal tourism, which integrates cultural revitalization, ecological conservation, and social development, was viewed as a major factor associated with local people's attitudes toward tourism development in Taiwan's aboriginal communities [12]. Several studies have determined that the economic, social, cultural, and environmental impact generated from the host-tourism exchange process influences residents' attitudes toward tourism development, demonstrating that the exchange value that local residents perceive determines the level of community acceptance of tourism development [20,22-25]. Previous studies conducted in Taiwan have revealed that indigenous people's perceived tourism benefits or costs influenced their attitudes toward aboriginal cultural tourism development [26-29]. For instance, Shih (2005) [29] identified that community intimacy positively affected residents' perceived cultural and economic impact from indigenous tourism in the Kele tribal community, which in turn influenced their support for tourism development. Liou (2013) [26] determined that ecotourism operations could assist in preserving and bequeathing local cultural activities and traditional crafts of the indigenous communities in the Tsou tribal community, thus enhancing their cultural self-identification and tribal cohesion. 


\subsection{Social Capital Theory}

The core concept of SCT is that social networks feature value, connections, and interactions between individuals; SCT also emphasizes norms of reciprocity and trustworthiness for facilitating coordination and cooperation to achieve goals [30,31]. SCT is defined as "the sum of the actual and potential resources embedded within, available through, and derived from the network of relationships possessed by an individual or social unit"; SCT can be divided into three dimensions, namely cognitive, structural, and relational capital [32,33]. Specifically, cognitive capital concerns a shared vision and shared beliefs [33-35]; structural capital refers to the overall connections within a network of social relationships (i.e., social interaction ties); and relational capital indicates the quality or strength of social ties consisting of trust, identification, and reciprocity.

SET can be applied to assess the impact of tourism benefits on local residents' support for tourism development. Within the social capital empowerment process, residents can establish trust in their local government through social connections, social networks, and civic engagement and therefore further support community-based tourism development [36]. This study adopted SET to estimate the impact of tourism benefits on aboriginal residents' attitudes toward their cultural tourism development, whereas SCT was integrated to embed clear rationales for strengthening the internalization process of the formation of residents' shared community values and understanding, thus enabling residents to trust each other and support tourism development. Park et al. (2012) [37] and Chang (2011) [15] have determined that tourism benefits could directly affect social capital in the context of community-based tourism. Moreover, Chang (2011) [15] argued that cognitive capital affected both structural and relational capital; structural capital influenced relational capital. Several studies have indicated that social capital is an accurate predictor of residents' attitudes toward tourism development [32,37-39]. On this basis, the following 10 hypotheses were proposed:

H1-1: Cultural tourism benefits have a positive impact on cognitive capital.

H1-2: Cultural tourism benefits have a positive impact on structural capital.

H1-3: Cultural tourism benefits have a positive impact on relational capital.

H1-4: Cultural tourism benefits have a positive impact on residents' attitudes toward aboriginal cultural tourism development.

H2-1: Cognitive capital positively influences structural capital.

H2-2: Structural capital positively influences relational capital.

H2-3: Cognitive capital positively influences relational capital.

H3-1: Cognitive capital positively influences residents' attitudes toward aboriginal cultural tourism development.

H3-2: Structural capital positively influences residents' attitudes toward aboriginal cultural tourism development.

H3-3: Relational capital positively influences residents' attitudes toward aboriginal cultural tourism development.

These 10 hypothesized relationships and our five constructs are illustrated in Figure 1. 


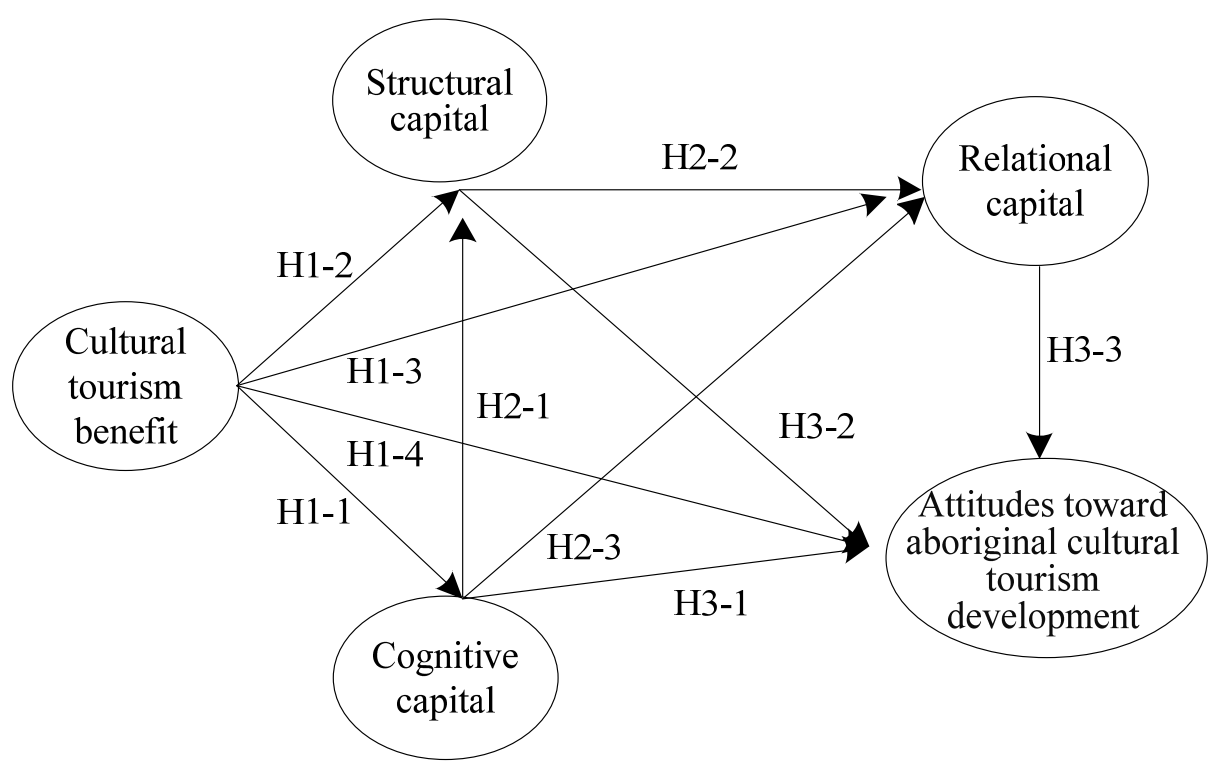

Figure 1. Proposed hypothetical model.

\section{Methods}

\subsection{Measurement Instrument and Data Collection}

A questionnaire was established on the basis of previous research, resulting in five constructs and 27 corresponding statements, measured using a 5-point Likert scale ranging from 1 (strongly disagree) to 5 (strongly agree). The questionnaire consisted of sociodemographic characteristics, a 5-item scale of cultural tourism benefits modified from prior studies [19,22,26,40-42], a 6-item scale of cognitive capital, a 6-item scale of structural capital, a 6-item scale of relational capital based on social capital literature [15,16,34,43-45], and a 4-item scale of attitudes toward aboriginal cultural tourism $[15,19,22,44]$. A pilot test with 50 questionnaires was conducted in the study area to evaluate the reliability and validity of the measurement scales. Adult Amis (also known as Pangcah) residents who lived in the Jian and Guangfu tourism-dependent communities were selected as the target participants of this study. A total of 1000 questionnaires were delivered, and 517 usable questionnaires were collected, yielding a 51.7\% overall response rate.

\subsection{Data Analysis}

SPSS 23 (IBM Corp, New York, NY, USA, 2013) and Amos 22 (IBM Corp, New York, NY, USA, 2013) were used to analyze the collected data. The sociodemographic characteristics of the participants revealed more males (54.8\%) than females (45.2\%). A greater percentage of respondents were aged $51-60(31.5 \%)$ than $31-40(23.8 \%)$ or $41-50(21.6 \%)$. The majority $(72.4 \%)$ were married, and most $(86.2 \%)$ had a senior high school degree or higher. Nearly half $(49.8 \%)$ of participants made their living from tourism, and one third were members of local community organizations.

\section{Results and Discussion}

The outcomes of measurement reliability testing showed that the Cronbach's alphas of the five constructs are higher than 0.7 [46]: (1) cultural tourism benefits scale, $\alpha=0.82$; (2) cognitive capital scale, $\alpha=0.89$; (3) structural capital scale, $\alpha=0.85$; (4) relational capital scale, $\alpha=0.88$; and (5) attitudes toward aboriginal cultural tourism scale, $\alpha=0.91$; thus, these five constructs are reliable. The proposed 10 hypotheses were tested through the measurement and structural models using Amos 22. Confirmatory factor analysis was first executed to assess the measurement model with five constructs. As shown in Table 1, all standardized factor loadings ranged from 0.71 to 0.86 , which were all higher 
than the 0.7 threshold, and all $t$-values were significant $(p<0.01)$, providing further evidence of the convergent validity [47]. The composite reliability values ranged from 0.86 to 0.91 , which were all higher than 0.70 , demonstrating acceptable internal consistency reliability [47]. The average variance extracted (AVE) values ranged from 0.57 to 0.66 , which were all over 0.50 , implying that the 27 observed variables have a high accuracy in determining the five latent variables [47]. The discriminant validity was evaluated by comparing the square root of the AVE for a given construct with the correlation coefficients between the construct and the other four constructs (Table 2). The results of these assessments of convergence validity and discriminant validity support the construct validity and reliability.

Table 1. Measurement Model $(N=517)$.

\begin{tabular}{|c|c|c|c|c|}
\hline Construct \& Indicators & SFL & $t$-Value & CR & AVE \\
\hline Cultural Tourism Benefits (CTB) & & & 0.91 & 0.66 \\
\hline 1. Preserve Amis cultural heritage & 0.75 & 12.70 & & \\
\hline 2. Preserve and inherit local cultural activities & 0.84 & 7.93 & & \\
\hline 3. Preserve and inherit traditional handicrafts & 0.83 & 8.77 & & \\
\hline 4. Enhance the community cohesion and collaboration & 0.84 & 7.17 & & \\
\hline 5. Make local people learn more about Amis tribe's culture and tradition & 0.81 & 7.40 & & \\
\hline Cognitive Capital (CC) & & & 0.90 & 0.60 \\
\hline 1. Reach community goals through mutual learning and cooperation & 0.77 & 13.48 & & \\
\hline 2. Help each other and share common values & 0.81 & 16.48 & & \\
\hline 3. Solve community's problems to achieve a common vision & 0.74 & 17.58 & & \\
\hline 4. Communicate with each other to avoid any conflicts & 0.75 & 15.63 & & \\
\hline 5. Collaborate and deepen residents' relationships & 0.77 & 14.61 & & \\
\hline 6. Act together to pursue common goals & 0.79 & 16.49 & & \\
\hline Structural Capital (SC) & & & 0.90 & 0.59 \\
\hline 1. I know many local people & 0.75 & 18.13 & & \\
\hline 2. I have good relationships with residents & 0.73 & 17.25 & & \\
\hline 3. The operation of the community is smooth & 0.79 & 16.33 & & \\
\hline 4. Our community development is well designed and planned & 0.86 & 18.36 & & \\
\hline 5. Residents could participate in the decision-making process of common affairs & 0.81 & 17.32 & & \\
\hline 6. Residents take an active part in the community development & 0.81 & 15.16 & & \\
\hline Relational Capital (RC) & & & 0.89 & 0.57 \\
\hline 1. I trust the mechanism of the community organization & 0.74 & 16.84 & & \\
\hline 2. The relationship between residents is cordial & 0.71 & 16.49 & & \\
\hline 3. Residents often receive a positive feedback from the community & 0.71 & 15.39 & & \\
\hline 4. Residents will help me solve problem encountered & 0.77 & 16.99 & & \\
\hline 5. I am proud to be part of this community & 0.82 & 16.07 & & \\
\hline 6. I have a stronger attachment to this community & 0.78 & 14.62 & & \\
\hline Attitudes toward Aboriginal Cultural Tourism (AAC) & & & 0.86 & 0.60 \\
\hline 1. I welcome tourists to visit our community & 0.75 & 12.05 & & \\
\hline 2. I support the development of aboriginal cultural tourism in our community & 0.81 & 11.31 & & \\
\hline 3. I am willing to introduce our community to visitors with my enthusiasm & 0.78 & 16.31 & & \\
\hline 4. I am willing to help strengthen the future development of our community & 0.75 & 18.16 & & \\
\hline
\end{tabular}

Note: SFL = Standardized Factor Loading $(\lambda), \mathrm{CR}=$ Composite Reliability, and AVE = Average Variance Extracted.

Table 2. Results of Discriminant Validities and Correlations.

\begin{tabular}{lccccc}
\hline Construct & $\mathbf{1}$ & $\mathbf{2}$ & $\mathbf{3}$ & $\mathbf{4}$ & $\mathbf{5}$ \\
\hline 1. CTB & $\mathbf{0 . 8 1 ^ { 1 }}$ & & & & \\
2. CC & $0.47^{* * *}$ & $\mathbf{0 . 7 8}$ & & & \\
3. SC & $0.52^{* * *}$ & $0.51^{* * *}$ & $\mathbf{0 . 7 8}$ & & \\
4. RC & $0.38^{* * *}$ & $0.43^{* * *}$ & $0.54^{* * *}$ & $\mathbf{0 . 7 6}$ & \\
5. AAC & $0.46^{* * *}$ & $0.52^{* * *}$ & $0.55^{* * *}$ & $0.49^{* * *}$ & $\mathbf{0 . 7 8}$ \\
\hline
\end{tabular}

${ }^{1}$ The bold values of the diagonal indicate the square root of Average Variance Extracted (AVE); Correlations are the values off the diagonal; ${ }^{* * *} p<0.001$. 
The model fit indices for the structural model reached an acceptable standard, with $x^{2} / \mathrm{df}=2.89$, AGFI $=0.92, \mathrm{NNFI}=0.91, \mathrm{CFI}=0.91, \mathrm{SRMR}=0.06$, and RMSEA $=0.06$. A summary of the model fit indices comprising both the measurement and structural model is presented in Table 3. Finally, the testing results of the 10 hypotheses, which are summarized in Table 4, indicated that most hypotheses were supported with a positive relationship, except for H2-3 and H3-1.

Table 3. Goodness-of Fit Indices of Measurement and Structural Models.

\begin{tabular}{ccccccc}
\hline Model & $\mathbf{x}^{2} / \mathbf{d f}$ & AGFI & NNFI & CFI & SRMR & RMSEA \\
\hline Measurement model & 2.82 & 0.94 & 0.93 & 0.94 & 0.05 & 0.06 \\
Structural model & 2.89 & 0.92 & 0.91 & 0.91 & 0.06 & 0.06 \\
Recommended level & $<3.00$ & $\geq 0.90$ & $\geq 0.90$ & $\geq 0.90$ & $<0.08$ & $<0.07$ \\
\hline
\end{tabular}

Note: Recommended level: $\mathrm{x}^{2} / \mathrm{df}<3$ [48]; the Adjusted Goodness of Fit Index (AGFI) $\geq 0.90$ [49]; the Non-Normed Fit Index (NNFI) $\geq 0.90$ [49]; the Comparative Fit Index (CFI) $\geq 0.90$ [50]; the Standardized Root Mean Residual $(\mathrm{SRMR})<0.080$ [49]; and the Root Mean Square Error of Approximation (RMSEA) < 0.07 [50].

Table 4. Results of Tested Hypotheses H1-1 H3-3.

\begin{tabular}{|c|c|c|c|c|}
\hline $\begin{array}{l}\text { Research } \\
\text { Hypothesis }\end{array}$ & Hypothesized Path & Path Coefficient & $t$-Value & Results \\
\hline H1-1 & $\begin{array}{l}\text { Cultural tourism benefits } \\
\rightarrow \text { Cognitive capital }\end{array}$ & 0.24 & $4.58^{* * *}$ & Supported \\
\hline $\mathrm{H} 1-2$ & $\begin{array}{l}\text { Cultural tourism benefits } \\
\rightarrow \text { Structural capital }\end{array}$ & 0.39 & $4.19^{* * *}$ & Supported \\
\hline H1-3 & $\begin{array}{l}\text { Cultural tourism benefits } \\
\rightarrow \text { Relational capital }\end{array}$ & 0.58 & $5.78^{* * *}$ & Supported \\
\hline $\mathrm{H} 1-4$ & $\begin{aligned} & \text { Cultural tourism benefits } \\
& \rightarrow \text { Attitudes toward aboriginal } \\
& \text { cultural tourism }\end{aligned}$ & 0.41 & $6.07^{* * *}$ & Supported \\
\hline $\mathrm{H} 2-1$ & $\begin{array}{l}\text { Cognitive capital } \\
\rightarrow \text { Structural capital }\end{array}$ & 0.61 & $8.16^{* * *}$ & Supported \\
\hline $\mathrm{H} 2-2$ & $\begin{array}{l}\text { Structural capital } \\
\rightarrow \text { Relational capital }\end{array}$ & 0.29 & $3.25^{* * *}$ & Supported \\
\hline $\mathrm{H} 2-3$ & $\begin{array}{l}\text { Cognitive capital } \\
\rightarrow \text { Relational capital }\end{array}$ & 0.07 & 0.51 & Not supported \\
\hline H3-1 & $\begin{array}{c}\text { Cognitive capital } \\
\rightarrow \text { Attitudes toward aboriginal } \\
\text { cultural tourism }\end{array}$ & 0.12 & 0.28 & Not supported \\
\hline H3-2 & $\begin{array}{c}\text { Structural capital } \\
\rightarrow \text { Attitudes toward aboriginal } \\
\text { cultural tourism }\end{array}$ & 0.21 & $2.39 *$ & Supported \\
\hline H3-3 & $\begin{array}{c}\text { Relational capital } \\
\rightarrow \text { Attitudes toward aboriginal } \\
\text { cultural tourism }\end{array}$ & 0.66 & $6.38^{* * *}$ & Supported \\
\hline
\end{tabular}

\section{Conclusions}

Growing visitor numbers for aboriginal cultural tourism have resulted in greater concerns about local residents' living environment and cultural preservation. Understanding local people's attitudes toward their future on the basis of social capital, therefore, is critical to sustainable tourism development. This study develops insights into how to evaluate indigenous cultural tourism development on the basis of the primary stakeholders' attitudes. First, this study investigated the effect of resident-perceived cultural tourism benefits, cognitive capital, structural capital, and relational capital on residents' attitudes toward aboriginal cultural tourism development. The testing results indicated that both cultural tourism benefits and social capital (structural and relational capital) were 
positively associated with residents' attitudes, except for cognitive capital. Residents' perceived cultural tourism benefits positively affects social capital, which in turn, establishes and strengthens residents' attitudes toward their future tourism development. This paper contributes to the literature by combining SET and SCT to investigate the determinants (i.e., tourism benefits and social capital) of aboriginal residents' attitude formation toward cultural tourism development. The findings also bridge the gap on whether social capital (i.e., cognitive, structural, and rational capital) plays a substantial mediating role between perceived benefit and attitudes, and this is partially consistent with prior studies $[15,32,39]$.

Structural capital affected relational capital, implying that community empowerment could facilitate establishing trust, identification, and reciprocity between residents and community organizations. In other words, more social interaction among indigenous residents should be encouraged to establish a stable and harmonious relationship in order to achieve common goals. Furthermore, the findings reveal that relational capital is a critical factor in predicting residents' attitudes as well as a mediator affecting the relationship between cognitive and structural capital, and residents' attitudes. In particular, relational capital had the strongest direct impact, and structural capital had the strongest indirect impact (through relational capital), indicating that the two were accurate predictors of residents' attitudes. This study provided empirical evidence to support the influence of social capital on residents' attitudes. Specifically, shared visions and beliefs facilitate building residents' social interaction which, in turn, strengthens residents' trust, identification, and reciprocity in supporting future development. On the basis of these results, one contribution of this study was to identify the process through which tourism benefits and social capital form the basis of residents' attitudes intergraded by two theories in the context of indigenous cultural tourism. The research results could provide indigenous community planners and developers with guidance for understanding residents' perceived tourism benefits and cost, social capital, and residents' attitudes toward cultural tourism development.

In contrast, cognitive capital was not associated with relational capital in this study, indicating that the shared vision and beliefs of cognitive capital had no direct impact on relational capital but still had an indirect impact on relational capital mediated by structural capital. This finding indicates that enhancing structural capital is critical for reducing the weakened social ties among residents. Therefore, a properly established social network platform between residents and their community is crucial for community planners seeking a consensus and for reaching cultural tourism development and growth goals. Additionally, cognitive capital was also determined not to influence residents' attitudes toward their cultural tourism development. Thus, community developers should integrate residents' shared vision and beliefs to reduce differences among residents and to increase their level of attachment to their community and thus their support for future tourism development.

This study has certain limitations in terms of the survey sites, study participation, and mediator and corresponding hypothesized link selection. First, the survey participants and communities were limited to Amis residents who lived in the Jian and Guangfu communities in Hualien, which restricts the generalizability of the results. Future researchers could consider a wider sample in different types of regions, as well as participants from different indigenous tribes with cross-cultural backgrounds to generalize the findings. Second, other antecedents and mediators or moderators that affect the consequences of the model context could be included to replicate these findings in other communities and population segments. Future researchers should apply a multidimensional tourism benefits or a social capital model to gain richer insights into how these antecedents influence indigenous people's attitudes and perceptions of cultural tourism development. A profound understanding of the determinant variables that affect residents' attitudes toward tourism development could help community developers and practitioners build a suitably considerate and comprehensive program for future tourism development. 
Author Contributions: Three authors contributed to this research: Chi-Ming Hsieh acted as the first author throughout the data analysis and manuscript drafting; Bi-Kun Tsai contributed to reviewing and revising the results and conclusions; and Han-Shen Chen improved the English and revised the paper. All authors read and approved the final manuscript.

Conflicts of Interest: The authors declare no conflicts of interest.

\section{References}

1. Richards, G. ATLAS Special Interest Group-Cultural Tourism Research Group. Available online: http: / /www.atlas-euro.org/sig_cultural.aspx\#2016 (accessed on 25 January 2017).

2. Destination British Columbia. Aboriginal Cultural Tourism. Available online: http://www.destinationbc. ca/getattachment/Research/Research-by-Activity/All-Sector-Profiles/Aboriginal-Cultural-TourismSector-Profile,-May-20/Tourism-Sector-Profile_AboriginalCulturalTourism_May2014.pdf.aspx (accessed on 19 April 2017).

3. Kesar, O.; Ferjanić, D. Development of cultural tourism in continental Croatia through reinforcing indigenous cultural identity. In Proceedings of the 4th International Conference "An Enterprise Odyssey: Tourism-Governance and Entrepreneurship", Cavtat, Hrvatska, 11-14 June 2008.

4. Nielsen, N.; Wilson, E. From invisible to indigenous-driven: A critical typology of research in indigenous tourism. J. Hosp. Tour. Manag. 2012, 19, 67-75. [CrossRef]

5. Smith, L.; Morgan, A.; van der Meer, A. Community-driven research in cultural heritage management: The Waanyi women's history project. Int. J. Herit. Stud. 2003, 9, 65-80. [CrossRef]

6. Robinson, D.W.; Twynam, D. Alternative tourism, indigenous peoples, and environment: The case of Sagarmatha (Everest) National Park, Nepal. Environments 1996, 23, 13-35.

7. Fan, L.; Li, Q. Influence of social capital, sense of place on the residents' attitudes toward ethnic village tourism development. J. Zhejiang Univ. (Sci. Ed.) 2016, 43, 337-344.

8. Cope, S.; Bailey, M.; Atkinson, R. Restructuring local government in Hampshire: A case of mistaken community identity? Public Adm. 1997, 75, 49-66. [CrossRef]

9. Li, W. Community decision making participation in development. Ann. Tour. Res. 2006, 33, 132-143. [CrossRef]

10. Mbaiwa, J.E. Enclave tourism and its socio-economic impacts in the Okavango Delta, Botswana. Tour. Manag. 2005, 26, 157-172. [CrossRef]

11. MacGillivray, A.; Walker, P. Local Social Capital: Making It Work on the Ground. In Social Capital: Critical Perspectives; Oxford University Press: Oxford, UK, 2000; pp. 197-211.

12. Chen, Y.F. The indigenous ecotourism and social development in Taroko National Park area and San-Chan tribe, Taiwan. GeoJournal 2012, 77, 805-815.

13. Chu, J.J. The changing status and subjectivity of the aborigines in Taiwan's labor markets. Int. J. Arts Sci. 2014, 7, 145-152.

14. Butler, R.; Hinch, T. Tourism and Indigenous Peoples: Issues and Implications; Routledge: London, UK, 2007.

15. Chang, K.C. Building the Model of Effecting Residents' Attitudes for Community Tourism Development: Based on the Social Exchange Theory and Communitarianism. Ph.D. Thesis, National Dong Hwa University, Hualien County, Taiwan, 2011.

16. Liu, J.; Qu, H.; Huang, D.; Chen, G.; Yue, X.; Zhao, X.; Liang, Z. The role of social capital in encouraging residents' pro-environmental behaviors in community-based ecotourism. Tour. Manag. 2014, 41, 190-201. [CrossRef]

17. Látková, P.; Vogt, C.A. Residents' attitudes toward existing and future tourism development in rural communities. J. Travel Res. 2012, 51, 50-67. [CrossRef]

18. Ap, J. Residents' perceptions on tourism impacts. Ann. Tour. Res. 1992, 19, 665-690. [CrossRef]

19. Andereck, K.L.; Valentine, K.M.; Knopf, R.C.; Vogt, C.A. Resident perceptions of community tourism impacts. Ann. Tour. Res. 2005, 32, 1056-1076. [CrossRef]

20. Nunkoo, R. Toward a more comprehensive use of social exchange theory to study residents' attitudes to tourism. Procedia Econ. Financ. 2016, 39, 588-596. [CrossRef]

21. Rasoolimanesh, S.M.; Jaafar, M.; Kock, N.; Ramayah, T. A revised framework of social exchange theory to investigate the factors influencing residents' perceptions. Tour. Manag. Perspect. 2015, 16, 335-345. [CrossRef] 
22. Gursoy, D.; Rutherford, D.G. Host attitudes toward tourism an improved structural model. Ann. Tour. Res. 2004, 31, 495-516. [CrossRef]

23. Andriotis, K.; Vaughan, R.D. Urban residents' attitudes toward tourism development: The case of Crete. J. Travel Res. 2003, 42, 172-185. [CrossRef]

24. Yoon, Y.; Gursoy, D.; Chen, J.S. Validating a tourism development theory with structural equation modeling. Tour. Manag. 2001, 22, 363-372. [CrossRef]

25. Ko, D.W.; Stewart, W.P. A structural equation model of residents' attitudes for tourism development. Tour. Manag. 2002, 23, 521-530. [CrossRef]

26. Liou, G.B. Ecotourism Cultural Impact Analysis. Ph.D. Thesis, Michigan State University, East Lansing, MI, USA, 2013.

27. Liu, T.M.; Lu, D.J. The cultural and ecological impacts of aboriginal tourism: A case study on Taiwan's Tao tribe. SpringerPlus 2014, 3, 1-9. [CrossRef] [PubMed]

28. Chen, P.T. A Study of Impacts on Aboriginal Residents Perception from Developing Tourism-A Case Study of Nan-Sun Village. Master's Thesis, Providence University, Taichung City, Taiwan, 2004.

29. Shih, P.C. A Study of the Relationship between Community Intimacy and Residents' Perception of Tourism Impact in Kele Tribal Community. Master's Thesis, Shih Hsin University, Taipei City, Taiwan, 2005.

30. Putnam, R. Bowling Alone: The Collapse and Revival of American Community; Simon and Schuster: New York, NY, USA, 2000.

31. Ecclestone, K.; Field, J. Promoting social capital in a risk society: A new approach to emancipatory learning or a new moral authoritarianism? Br. J. Sociol. Educ. 2003, 24, 267-282. [CrossRef]

32. Zhao, W.; Ritchie, J.B.; Echtner, C.M. Social capital and tourism entrepreneurship. Ann. Tour. Res. 2011, 38, 1570-1593. [CrossRef]

33. Nahapiet, J.; Ghoshal, S. Social capital, intellectual capital, and the organizational advantage. Acad. Manag. Rev. 1998, 23, 242-266.

34. Stewart, K.J.; Gosain, S. The moderating role of development stage in free/open source software project performance. Softw. Process Improv. Pract. 2006, 11, 177-191. [CrossRef]

35. Tsai, W.; Ghoshal, S. Social capital and value creation: The role of intrafirm networks. Acad. Manag. J. 1998, 41, 464-476. [CrossRef]

36. Nunkoo, R.; Ramkissoon, H. Power, trust, social exchange and community support. Ann. Tour. Res. 2012, 39, 997-1023. [CrossRef]

37. Park, D.B.; Lee, K.W.; Choi, H.S.; Yoon, Y. Factors influencing social capital in rural tourism communities in South Korea. Tour. Manag. 2012, 33, 1511-1520. [CrossRef]

38. Macbeth, J.; Carson, D.; Northcote, J. Social capital, tourism and regional development: SPCC as a basis for innovation and sustainability. Curr. Issues Tour. 2004, 7, 502-522. [CrossRef]

39. Yoon, Y.S. A study on tourism development attitudes and supports based on social capital in agricultural tourism area. J. Rural Tour. 2009, 16, 41-61.

40. Besculides, A.; Lee, M.E.; McCormick, P.J. Resident's perceptions of the cultural benefits of tourism. Ann. Tour. Res. 2002, 29, 303-319. [CrossRef]

41. Clifton, J.; Benson, A. Planning for sustainable ecotourism: The case for research ecotourism in developing country destinations. J. Sustain. Tour. 2006, 14, 238-254. [CrossRef]

42. Fotiou, S.; Buhalis, D.; Vereczi, G. Sustainable development of ecotourism in small islands developing states (SIDS) and other small island. Tour. Hosp. Res. 2002, 4, 79-88. [CrossRef]

43. Adler, P.S.; Kwon, S.W. Social capital: Prospects for a new concept. Acad. Manag. Rev. 2002, 27, 17-40.

44. Gilchrist, A. The Well-Connected Community: A Networking Approach to Community Development; Policy Press: Bistrol, UK, 2009.

45. Kankanhalli, A.; Tan, B.C.; Wei, K.K. Contributing knowledge to electronic knowledge repositories: An empirical investigation. MIS Q. 2005, 29, 113-143.

46. Nunnally, J. Sychometric Theory; McGraw-Hill: New York, NY, USA, 1978.

47. Fornell, C.; Larcker, D. Structural equation models with unobservable variables and measurement error: Algebra and statistics. J. Mark. Res. 1981, 18, 382-388. [CrossRef]

48. Kline, R.B. Principles and Practice of Structural Equation Modeling; Guilford Press: New York, NY, USA, 2004. 
49. Hu, L.T.; Bentler, P.M. Cutoff criteria for fit indexes in covariance structure analysis: Conventional criteria versus new alternatives. Struct. Equ. Model. Multidiscip. J. 1999, 6, 1-55. [CrossRef]

50. Byrne, B.M. Structural Equation Modeling with Lisrel, Prelis, and Simplis: Basic Concepts, Applications, and Programming; Lawrence Erlbaum Associates: Mahwah, NJ, USA, 1998.

(c) 2017 by the authors. Licensee MDPI, Basel, Switzerland. This article is an open access article distributed under the terms and conditions of the Creative Commons Attribution (CC BY) license (http:/ / creativecommons.org/licenses/by/4.0/). 